\title{
The Bioprotective Efficacy of Hibiscus sabdariffa (Roselle), Moringa oleifera (Moringa) Zingiber officinale (Ginger) and Telfairia occidentalis ('Ugwu') in the Livers and Kidneys of Rattus norvegicus (Albino rats) Exposed to Cement dust
}

\author{
T. Yahaya, J. Okpuzor and E. O Oladele \\ Department of Cell Biology and Genetics, University of Lagos.
}

\begin{abstract}
IORS ENVIRONMENT Roselle, moringa, ginger and 'ugwu' are food plants eaten as vegetables or spices in most communities in Nigeria. The protective efficacy of the extracts of these plants was evaluated in the livers and kidneys of albino rats exposed to cement dust around a polluted environment. Six groups of rats comprising 18 rats each were exposed to cement dust at $200 \mathrm{~m}$ from a cement factory in Southwest, Nigeria. The control group was administered distilled water, while the test groups were fed with 400 $m g \mathrm{~kg}^{-1}$ ethanol extracts of roselle, moringa, ginger, 'ugwu' and a mixture of the extracts of the plants for 180 days. They were subsequently sacrificed for the histopathological studies of the harvested livers and kidneys. The organs of the control rats presented abnormal cellular architecture, vascular congestion and inflammation whereas normal cellular pattern, slight inflammation and no vascular congestion were evident in the group that received the mixture. However, the organs of the rats administered the extracts of roselle, moringa, ginger and 'ugwu' respectively, presented normal and moderate to severe conditions of the histopathological abnormalities observed in the control group. These results suggest that these food plants could play a role in healthcare delivery, through bioprotection of the livers and kidneys of inhabitants of polluted environments, and may also be useful in ameliorating the effects of occupational hazards.
\end{abstract}

Keywords: Cement dust, Extract, Bio-protective, Histopathological, Ameliorate.

\section{Introduction}

Environmental pollution from cement production activities is causing increasing concern globally due to its adverse effects on air, water and soil. During the last few decades, the emission of dust from cement industries has been increased two-folds due to expansion of more cement plants to satisfy the high demand for cement for infrastructure (Raajasubramnran, et al, 2011). Cement dust is a mixture of calcium, silicon, aluminium, manganese and iron. In addition, cement dust produced from kilns fuelled by burning of hazardous wastes may contain lead, chromium, cadmium, arsenic and zinc (Yahaya and Okpuzor, 2011). The majority of these elements, when above regulatory limits, become potentially harmful to the biotic and abiotic components of the environment. These elements have been implicated in many diseases, including blood, genetic and respiratory diseases, lung, liver and kidney damage, and skin and eye defects (Akinola et al, 2008, Calistus et al, 2002, Yahaya et al, 2011 and Zeleke et al, 2010). Despite these health hazards, cement remains the most popular material for building and infrastructural growth, attributable to its availability, durability, reliability and affordability. Hence, the need to ameliorate the health effects of cement dust exposure on man and animal is necessary.

Pollution prevention and control strategies in the cement industry have not recorded much success, particularly in the developing countries. Some studies carried out on workers, artisans, and residents of cement plants showed that they are suffering from health problems suspected to be the effects of cement dust exposures. Mojimoniyi et al. (2007) reported that cement factory workers in Sokoto, Nigeria, were adversely affected by cement dust pollution despite taking preventive measures. With the current trend in plant-based nutrition, there is a pressing need to evaluate the chemopreventive and bio-protective efficacy of some plants in order to maintain the growth of the industry.

Since ancient times, plants have been employed in the treatment of a number of diseases. Several experimental studies and to a lesser extent, clinical trials have also emphasized the roles of plants in the treatment of a variety of disorders. Some archaeological evidence shows that some plants such as milk thistle (Silybum marianum), red clover (Trifolium proteins), and dandelion (Taraxacum officinale) have been employed in the past to prevent or detoxify the body (Mindell, 1992). However, attention was shifted away from plant medicine with the evolution of synthetic-drugs and modern medicine (Mindell, 1992 and Wu et al, 1996). However, due to the high cost and side effects of prescription medications, there is a renewed interest in natural remedies (Steven, 2011). This study evaluates the effectiveness and potency of some food plants in protecting the livers and kidneys of albino rats exposed to cement dust. 
Animal Husbandry

\section{Materials}

One hundred and fifty albino rats (Rattus norvegicus) weighing between 185 and $200 \mathrm{~g}$ were purchased from the Department of Biochemistry, University of Ibadan in August 2009. The rats were left for about seven days in cages to acclimatize to the ambient environment before commencing the research. Pellet feeds from the F. A Feeds industry, Lagos and water were given to the rats ad libitum.

\section{Source of the Plant Materials}

The plant materials- roselle (Hibiscus sabdariffa L.), moringa (Moringa oleifera L.), ginger (Zingiber officinale R.), and 'ugwu' (Telfairia occidentalis H.) were purchased from Ketu in Lagos metropolis. They were identified by a curator, Mr. Odewo T. Kolawole, in the Department of Botany, University of Lagos. The voucher numbers of the authenticated samples are LUH 4394, LUH 4558, LUH 4396 and LUH 4395 for roselle, moringa, ginger, and 'ugwu', respectively.

\section{Preparation of the Plant Materials}

Fresh leaves of the plant materials were washed gently to remove impurities and air-dried under shade for one week. The dried leaves were milled into a powder using laboratory mill, Norris Limited, Poole, England at the Department of Pharmacognosy, University of Lagos. Besides the powder of individual plant materials produced, a mixture of the plant materials was also formed by mixing the four parts each of the ground plant materials in the ratio 1:1:1:1. The ground plant materials were then stored in desiccators before use.

\section{Preparation of the Plant Extracts}

The bioactive compounds were extracted from the plant materials using the method of Okigbo and Ogbonnaya (2006). Fifty grams (50 g) powder of each plant material and the mixture were put in $500 \mathrm{ml} 95 \%$ cold ethanol and was allowed to stand for 72 hours. The extracts thus obtained were filtered with muslin cloth and evaporated to dryness at a temperature of $40 \pm 2^{\circ} \mathrm{C}$. The resulting dried extracts of each plant material yielded $6.6 \mathrm{~g}, 6.5 \mathrm{~g}, 6.2 \mathrm{~g}, 5.9 \mathrm{~g}$, and $6.1 \mathrm{~g}$ of roselle, moringa, ginger, 'ugwu' and mixture, respectively. These dry extracts were reconstituted in water and were the decoctions used for the experiment.

\section{Acute Toxicity Test}

The acute toxicity of the crude extracts of the plants was measured using the 'Classical $\mathrm{LD}_{50}$ ' method described by Gabriel et al. (2008). Albino rats (36) of both sexes weighing between 183 and $205 \mathrm{~g}$ were used for the studies. The rats were randomly distributed into six groups of 6 rats each and were made to fast for 12 hours before commencing the study. The control group received only distilled water, while the test groups were orally administered doses of $200,400,500,700,1500$, and $2000 \mathrm{mg} \mathrm{kg}^{-1}$ of the crude extracts. The general symptoms of toxicity were monitored and recorded for each group within 24 hours.

\section{Dosage Administered to the Rats}

The acute toxicity test showed the plant extracts were nontoxic to the rats even at a dose of $2000 \mathrm{mg}$ $\mathrm{kg}^{-1}$. However, based on a previous study by Adedapo et al. (2009), a dose of $400 \mathrm{mg} \mathrm{kg}^{-1}$ was chosen. The study showed that moringa extracts performed best on the biochemical and haematological parameters of rats at the said dose.

\section{Study Design}

\section{Methods}

The rats were placed into six groups of 18 rats each. Group one was the control, while groups two through six formed the test rats. The livers and kidneys of the rats were harvested for histopathological examinations before commencing the experiment. The entire rats were thereafter exposed to cement dust at a cement factory in Shagamu, Southwestern, Nigeria. Groups two through six of the rats were treated with 400 $\mathrm{mg} \mathrm{kg}^{-1}$ ethanol extracts of roselle, moringa, ginger, 'ugwu' and mixture of the plants, respectively for 180 days. Group one received only distilled water for the same duration. The livers and kidneys of the rats were again harvested for histopathological studies at the end of the exposure.

\section{Histopathology Studies}

The liver and kidney tissues of the rats were prepared for histopathology examination using the method of Taylor et al., 2003..

About 3-5 mm thick samples were cut from the livers and kidneys of the rats and the tissues were then fixed using bound's fluid. The tissues were dehydrated gradually through a series of increasingly concentrated ethanol/water mixture and finally in pure ethanol. Since alcohol does not mix with common embedding media, 
it was replaced with xylol. The tissues were then embedded in molten wax and allowed to set. Embedded tissues were sectioned using a microtome. Five (5) micrometers thick were cut from the wax-embedded tissues using a knife. The wax was dissolved away, and tissues partially dehydrated before staining.

The tissues were then stained using mercury oxide at low concentrations. The stained tissues on glass slides were covered tightly with cover-slips and viewed under a light microscope.

\section{Results}

Plates 1-7 show the bioprotective efficacy of the plant extracts on the liver tissues of the albino rats exposed to cement dust for 180 days. Plate 1 showed the liver tissues of the rats before exposure showing normal hepatocyte, normal portal tracts, and normal central vein. The control rats that received distilled water only showed severe vascular congestion (Plate 2). The rats that were fed with roselle extract showed normal hepatocyte, and mild vascular congestion (Plate 3). The rats that received moringa, ginger, 'ugwu' and mixture extracts showed no abnormality (Plates 4, 5, 6 and 7), respectively.

Plates 8-14 show the bio-protective efficacy of the plant extracts on the kidney tissues of the albino rats exposed to cement dust for 180 days. Plate 8 showed the kidney tissues of the rats before exposure showing normal glomerulus, normal interstitial, and normal tubules. The control rats that received distilled water only showed severe interstitial inflammation and haemorrhage (Plate 9), while the rats that were fed with roselle extract had mild inflammation (Plate 10). However, no abnormality was observed in the rats that were given moringa, ginger, 'ugwu' and mixture (Plates 11, 12, 13 and 14), respectively.

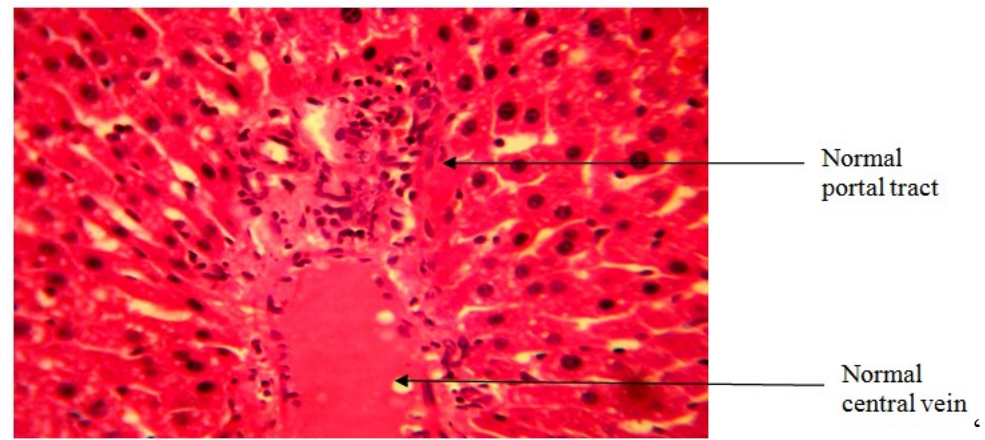

Plate 1: Photomicrograph of the liver tissues of the albino rats before exposure (X 400).

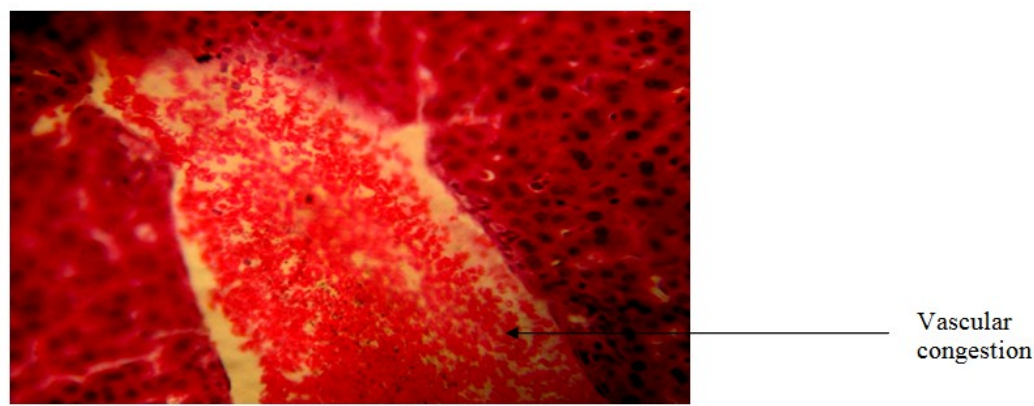

Plate 2: Photomicrograph of the liver tissues of the control albino rats at the end of exposure (X400).

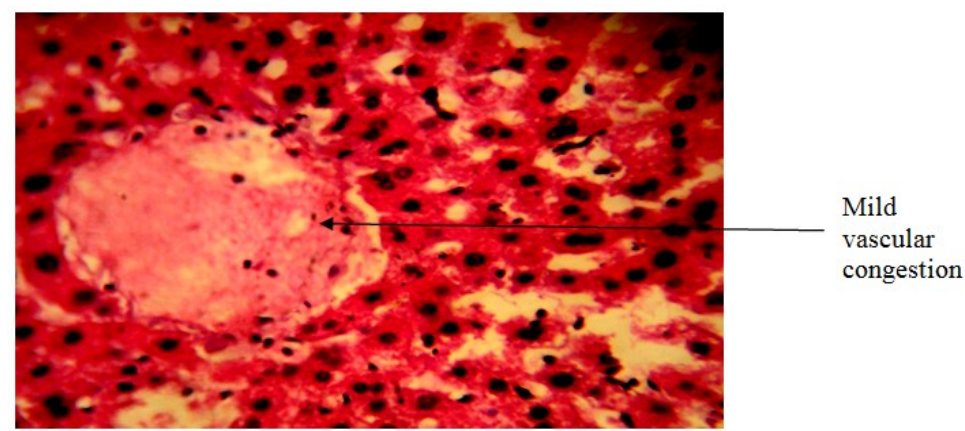

Plate 3: Photomicrograph of the liver tissues of the exposed albino rats fed with roselle extract (X400). 


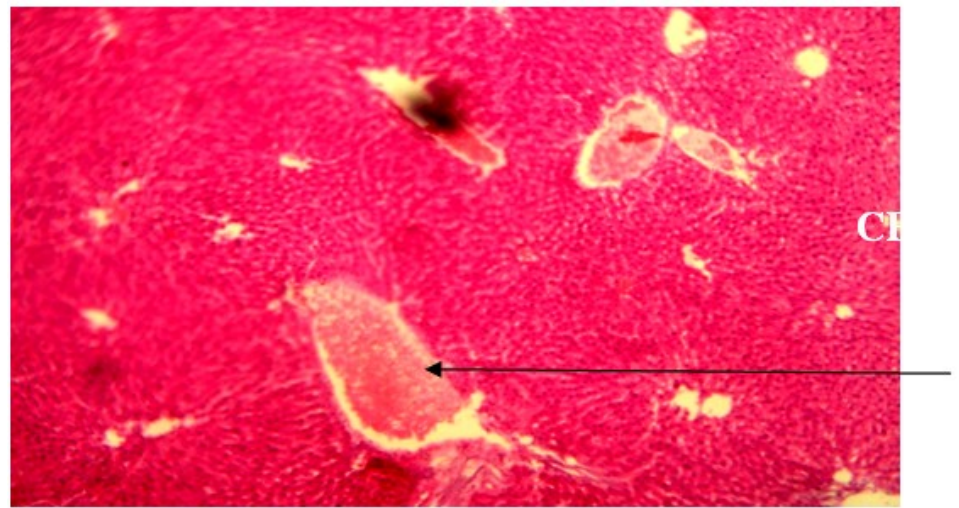

Normal

central vein

Plate 4: Photomicrograph of the liver tissues of the exposed albino rats fed with moringa extract (X400).

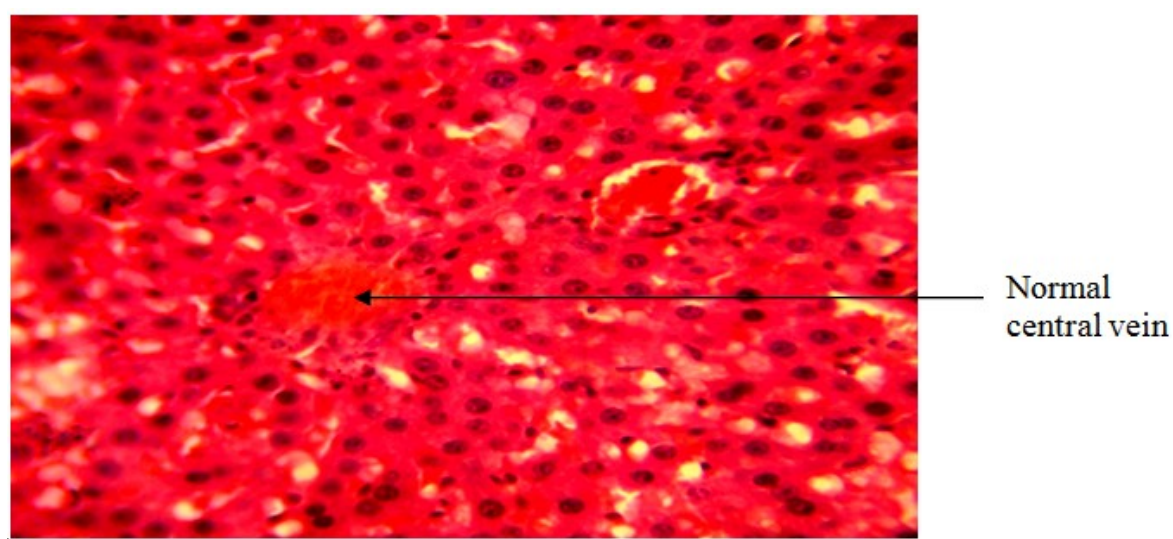

Plate 5: Photomicrograph of the liver tissues of the exposed albino rat fed with ginger extract (X400).

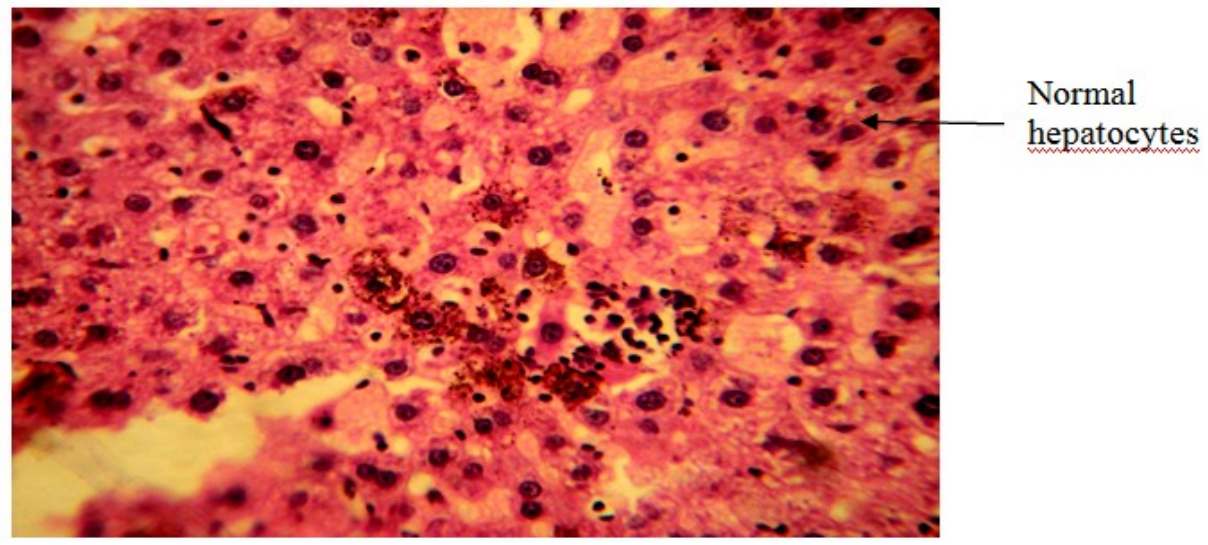

Plate 6: Photomicrograph of the liver tissues of the exposed albino rats fed with 'ugwu' extract (X400).

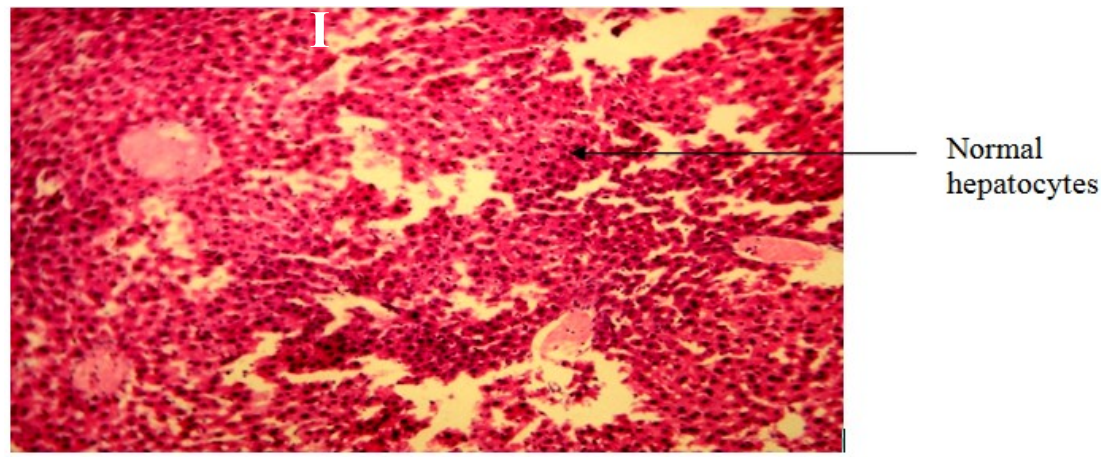

Plate 7: Photomicrograph of the liver tissues of the exposed albino rats fed with mixture extract (X400). 


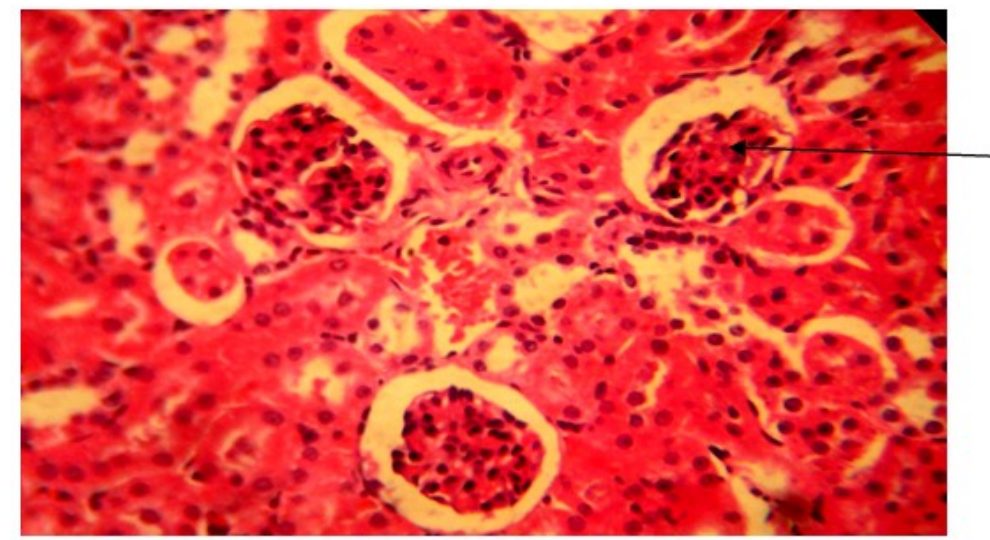

Normal

glomerulus

Plate 8: Photomicrograph of the kidney tissues of the albino rats before exposure (X400).

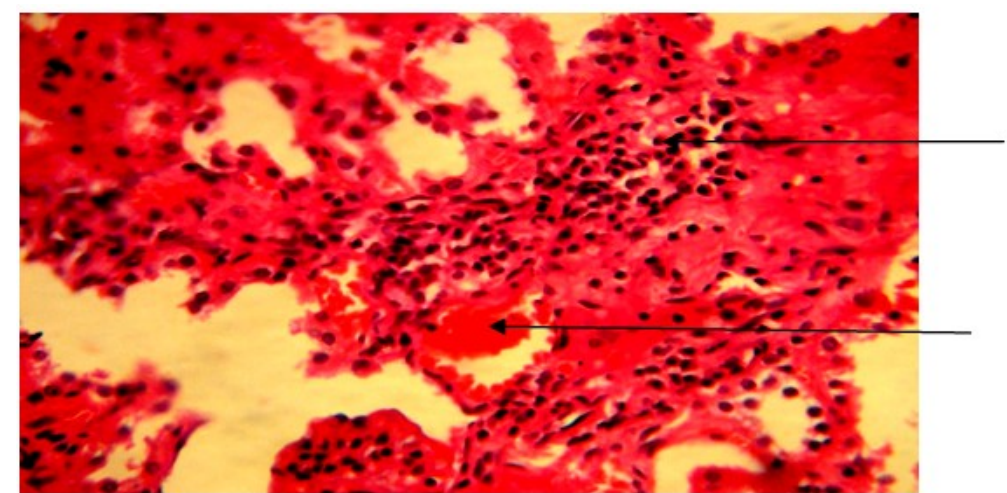

Severe

inflammation

Haemorrhage

Plate 9: Photomicrograph of the kidney tissues of the control albino rats at the end of exposure (X400).

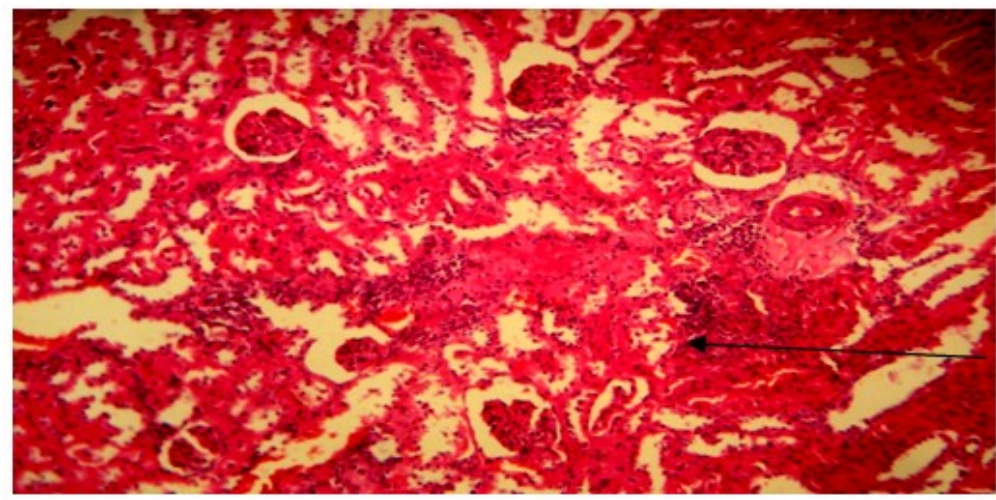

Mild

inflammation

Plate 10: Photomicrograph of the kidney tissues of the exposed albino rats fed with roselle extract (X400).

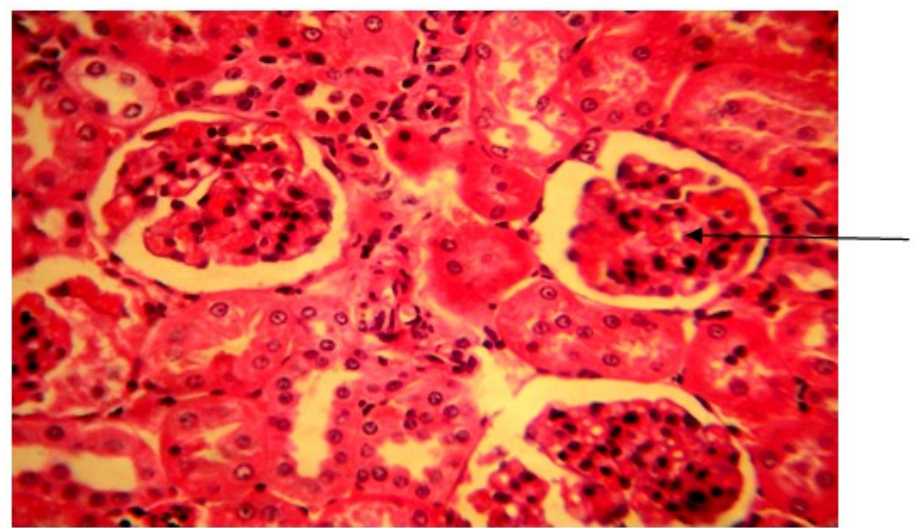

Normal

glomerulus

Plate 11: Photomicrograph of the kidney tissues of the exposed albino rats fed with moringa extract (X400). 


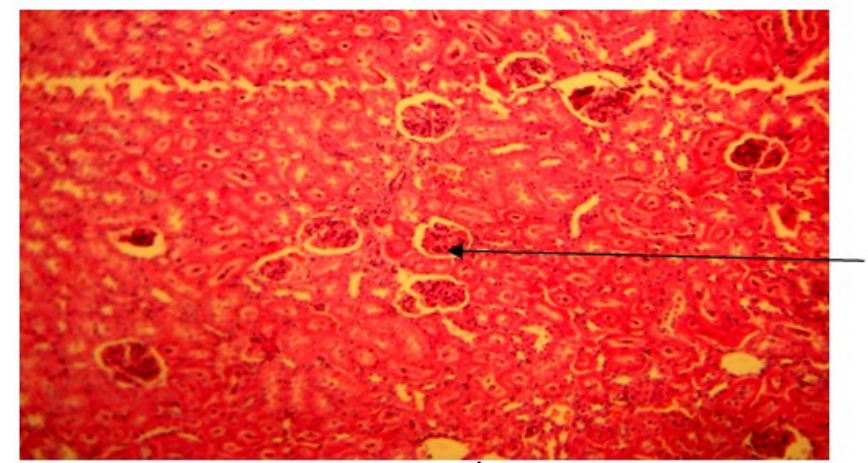

Normal

glomerulus

Plate 12: Photomicrograph of the kidney tissues of the exposed albino rats fed with ginger extract (X400).

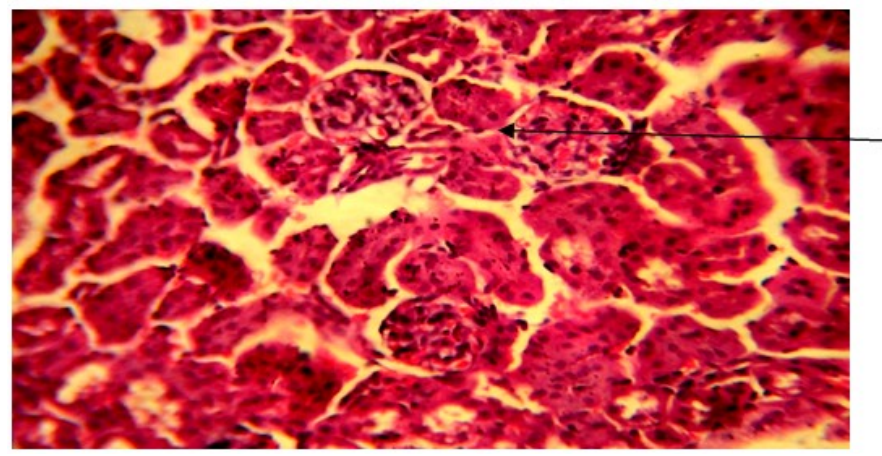

Normal

glomerulus

Plate 13: Photomicrograph of the kidney tissues of the exposed albino rats fed with 'ugwu' extract (X400).

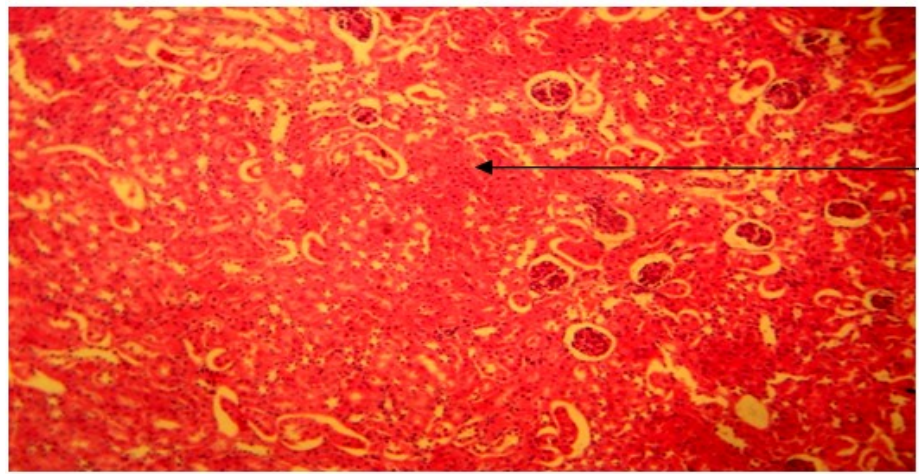

Normal

glomerulus

Plate 14: Photomicrograph of the kidney tissues of the exposed albino rats fed with mixture extract (X400).

\section{Discussion}

Some elements in cement dust have been implicated in a lot of diseases, including multi-organ damage (Yahaya and Okpuzor, 2011). Fortunately, the potency of some herbs and food plants in reducing the effects of pollutants have been reported (Yahaya et al., 2012).

The marked histological damage observed in the liver and kidney tissues of the exposed rats treated only with distilled water showed deleterious interactions between the tissues and the toxic elements in the cement dust. Some elements in cement dust are suspected to be involved in the pathogenesis of the histological damage. Yahaya and Okpuzor (2011) reported high concentrations of calcium in the lung tissues of albino rats exposed to cement dust, which could have induced toxicity. Fan et al. (2007) stated that although calcium is important in metabolism, excess amounts can cause brain damage. Silicon, aluminium, and chromium compounds, also found in the tissues of the exposed rats in high concentrations in the same study, have been implicated in silicosis, increased risk of cancer, and tissue damage (ATSDR, 2010; Yahaya et al., 2011). The normal and moderate to the mild histology of the exposed albino rats administered with the plant extracts may be the outcome of the chemopreventive and protective activities of phytochemicals and phytonutrients such as flavonoids, glycosides, tannins, saponins, ascorbic acid, zinc, and magnesium in the plant extracts. Flavonoids in Azadirachta indica leaves have been reported to prevent or neutralize free-radicals and toxic elements, which 
attack the cells and tissues of animals and damage it (Krishnaiah et al, 2008). Saponins in plant extracts have been shown to assist humans to prevent or fight tumour cells, particularly lung and blood cancers caused by toxic substances (Barakat et al., 1993). Ascorbic acid is a strong antioxidant which activates the functions of all the cells, protects and removes toxic substances from the body and intervenes in the regeneration of damaged tissues (Poornima and Ravishankar, 2009). The presence of tannins and terpenoids in Hibiscus Rosa-sinensis has been explained for its involvement in tissue healing and cell regeneration processes (Nayak et al., 2007; Okwu and Josiah, 2006).

\section{Conclusion}

The food plants used in this study are bio-protective and can protect the cells and tissues of rats exposed to cement dust. People living near cement plants should include these food plants in their diets to prevent internal organ damage. Government at all levels should also incorporate phytomedicine in pollution control strategies.

\section{References}

[1] Adedapo, A.A., O.M. Mogbojuri and B.O. Emikpe. 2009. Safety evaluations of aqueous extracts of the leaves of Moringa oleifera in rats. Journal of Medicinal Plants Research. 3(8): 586-591.

[2] Agency for Toxic Substances and Diseases Registry (ATSDR). 2011. Medical Management Guidelines for Nitrogen Oxides. Toxic substances Portal- Nitrogen oxide. http://www.atsdr.cdc.gov/MMG/MMG.asp?id=394\&tid=69 (Accessed on 07/06/2011).

[3] Akinola, M.O., N.A. Okwok and T. Yahaya. 2008. The effects of cement dust on Albino rats (Rattus norvegicus) around West African Portland cement Factory in Sagamu, Ogun State, Nigeria. Research Journal of Environmental Toxicology. 2(1): 1-8.

[4] Barakat, M. Z., S. K. Shahab, N. Darwin, E. L. Zahemy. 1993. Determination of ascorbic acid from plants. Journal of Analytical Biochemistry. 53: 225-245.

[5] Calistus, A.L., K. Kumar, S. Sudha and J. Raichel. 2002. Haematological and Cytogenetic studies in workers occupationally exposed to cement dust. International Journal of Human Genetics. 2(2): 95-99.

[6] Fan, Y., L. Shi, Y. Gu, Y. Zhao and J. Xie. 2007. Pretreatment with PTD- calbindin D28k alleviates rat brain injury induced by ischemia and reperfusion. Journal of Cerebral Blood Flow Metabolism. 27: 719-728.

[7] Gabriel, O., N. Harrision, O. Okey and A. Ukoha. 2008. Changes in Lipid and Haematological Profile of Aqueous Ethanolic Extracts of Alstonia Boonei in rats. The Internet Journal of Haematology. 4:1.

[8] Krishnaiah, D., T. Devi, A. Bono and R. Sarbatly. 2008. Studies on phytochemical constituents of six Malaysian medicinal plants. Journal of Medicinal Plants Research. 3(2): 067-072.

[9] Mindell, E. 1992. Earl Mindell's Herb Bible. pp304. Simon and Schuster, New York.

[10] Mojimoniyi, F.B.O, I.A. Merenu, M.T.O. Ibrahim and C.H. Njoku. 2007: The Effects of cement dust exposure on haematological and liver function parameters of cement factory workers in Sokoto, Nigeria. Nigeria Journal of Physiological Science. 23(1-2): 111 -114 .

[11] Nayak, B. S., S. S. Raju, F. A. Orette, A. V. O. Rao. 2007. Effects of Hibiscus Rosa sinensis L. on Wound Healing Activity: A Preclinical Study in a Sprague Dawley Rat. International Journal of Low and Extreme Wounds. 6(2): 76-81.

[12] Okigbo, R. N. and N. O. Ogbonnaya. 2006. Antifrugal effects of two tropical leaf extracts (Ocinium gratissimum and Aframomum melegueta) on postharvest yam (Dioscorea spp.) rot. African Journal of Biotechnology. 5(9): 727-731.

[13] Okwu, D. E and C. Josiah. 2006. Evaluation of the chemical composition of two Nigerian medicinal plants. African Journal of Biotechnology. 5 (4):357-361.

[14] Poornima, G.N. and R. V. Ravishankar. 2009. Evaluation of phytonutrients and vitamin contents in a wild yam, Dioscorea belophylla (P.). African Journal of Biotechnology. 8 (6): 971-973.

[15] Raajasubramanian, D., P. Sundaramoortha, L. Baskaran, K. SankarGanesh, A.L.A. Chidambaram and M. Jeganathan. 2011. Cement dust pollution on growth yield attribute of groundnut (Arachis hypogaea L.). International Multidisciplinary Research Journal. 1(1):3136. http://www.irjs.info/IRMJ-Ecology. (Accessed on 17/06/2011).

[16] Steven, D. E. 2011. Herbal Medicine Overview. University of Maryland Medical Center, 22 S. Greene Street, Baltimore. www.umm.edu/altmed/articles/herbal- medicine-000351.htm. (Accessed on 24/03/2013).

[17] Taylor, D. J, N.P.U. Green and G.W. Stout. 2003: Microscope Techniques. Biological Science.

[18] 3rd Edn. Cambridge University Press, U. K. pp 163-164.

[19] Wu, C.G., R.A. Chamuleau and K.S. Bosch. 1996. Potential effects of Silymarin on Rat Liver injury induced by Ischemia. Virchow Archives B. 64(5):259-263

[20] Yahaya and Okpuzor. 2011. Variation in cement dust exposure in relation to distance from cement factory. Research Journal of Environmental Toxicology. 5: 203-212.

[21] Yahaya, T., J Okpuzor and T. F. Adedayo. 2011. Investigation of general effects of cement dust to clear the controversy surrounding its toxicity. Asian Journal of Scientific Research. 4: 315-325.

[22] Yahaya, T., J. Okpuzor and T. Ajayi. 2012. The Prophylactic Efficacy of Roselle (H. sabdariffa), Moringa (M. oleifera), Ginger (Z. officinale) and 'Ugwu' (T. occidentalis) on the Hematology and Serum protein Of Albino Rats (Rattus ncivigicus) Exposed †o Cement dust. Research Journal of Medicinal Plants, 6: 189-196.

[23] Zeleke, Z.K., B.E. Moen and M. Bratveit. 2010. Cement dust exposure and acute lung function: A cross shift study. BMC Pulmonary Medicine. 10 (1): 19. 